\title{
Implementing Generative Learning Model to Enhance 2nd year English Majors' Critical Reading and Writing Skills
}

\section{Dr. Howida Mostafa. A. Masoud}

Assistant Professor in Methodology and Instruction Dept., Faculty of Education, Minia University, El-Minia, Egypt

\section{Abstract}

The present study was carried out to investigate the
effectiveness of using a Generative Learning Model
(GLM) on fostering 2nd year English Majors' critical reading and writing skills at Faculty of Education, Minia University. A quasi-experimental pretest-posttest control group research design was employed. A language teaching program based on GLM was developed by the researcher and used with the treatment group, whereas, the conventional lecture method was used with the non-treatment group. Sixty female and male students were randomly chosen and divided into two groups: the treatment and the non-treatment. A critical reading questionnaire, a critical writing questionnaire, a language teaching GLM-based program, a pre-post critical reading test (CRT) and a prepost critical writing test (CWT) were used as instruments of the study. Ttest was used to analyze the statistical data of the study and Eta-Squared to measure the effect size of the GLM. Results revealed that the treatment group significantly outperformed the non-treatment one on the post-performance of both the critical reading and writing tests. Discussion of these findings, recommendations and suggestions for further research are presented.

Keywords : Generative Learning Model, Critical Reading and Critical Writing.

\section{Introduction}

Teachers should basically care about the kind of learning introduced to students in the classroom. Learning should not only emphasize memorization of knowledge but also the active role of the learners in constructing and organizing their knowledge. Teachers should help students to develop their critical thinking skills in a more enjoyable learning environment. To achieve this, innovative methods, activities and techniques 
should be adopted for more involvement and engagement of students in their learning. Students need to learn to be knowledge builders not knowledge seekers. Generative Learning Model (GLM) is a promising method which provides such a supportive learning atmosphere.

\section{What is Generative Learning Model (GLM)?}

The term Generative Learning was first coined by Wittrock (1974) who introduced the GLM as a type of instruction in which learners are considered "forefront" of the learning process. Learners actively engaged in constructing their own interpretations of information, and inferences are drawn from them. In his model, key processes such as prior knowledge and experience, motivation, cognition and generation in meaningful learning were emphasized (Fiorella and Mayer, 2016). Wittrock (1992) stated that "although a student may not understand sentences spoken to him by his teacher, it is highly likely that a student understands sentences that he generates himself."... "Learners generate perceptions and meanings that are consistent with their prior knowledge".

The core notion of Wittrock's GLM is that meaningful learning is occurred when learners generate their own cognitive meanings for newly learned materials and make sense of them based on their prior knowledge. GLM is a learner-centered approach where learners' experiences and views are of great importance (Anderman, 2010). Generative learning is seen to be a process of generating understanding through which an inner relation among different key elements i.e. knowledge, experience and concepts of learning material is being established (Hanke, 2012). According to GLM, the learners' brain does not passively receive information but actively interprets, clarifies, generates and makes connections of it. It makes an epistemological shift from lower order level of thinking to higher order level.

Importance of applying GLM in teaching was clearly confirmed by advocates of the model (Wittrock, 1992, Fiorella and Mayer, 2016, Atsuwe and Anyebe, 2016 and Prawita et al., 2019) as it: 
- Offers a positive instructional learning environment to work independently.

- Assists students to generate their own ideas and interpretation.

- Helps the learners' mental process to be active to make links between prior knowledge and newly learned one.

- Encourages self-efficacy of students

- Encourages higher order level of thinking.

- Emphasizes knowledge formation by students.

- Empowers students with the ability to express their own viewpoints.

For the importance and effectiveness of GLM in teaching, the present study is adopting Mayer's model (2014) which is closely related to Wittrock's model. It consists of three basic cognitive processes: Select-Organize-Integrate (SOI) as shown in the following figure:

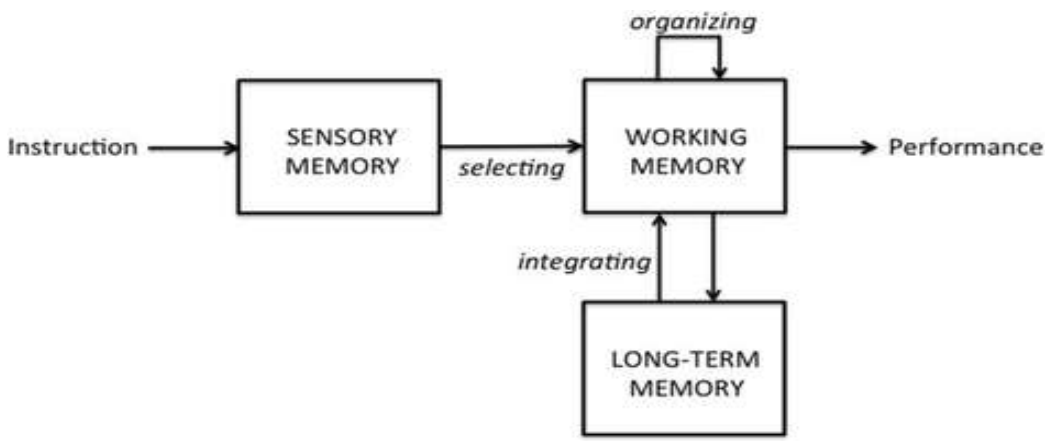

The above figure explains the GLM as (Cited in Mayer, 2014):

- The Select stage: Students receive information from outside in the form of instruction and enters into their sensory memory. When they are aware of the incoming information, they transfer the relevant material to the working memory for further processing of work.

- The Organize stage: In the working memory, students reorganize the selected information to form a coherent and cognitive structure to build connections and relationships among current ideas. 
- The Integrate stage: Students can call existed information from long-term memory and integrate the newly learned information and present a new structure to be used in new different situations.

The GLM implies some basic learning strategies such as: summarizing, mapping, outlining, getting the main idea of a text, teaching, inferring and paraphrasing. The core aim of these strategies is to encourage the learners' mind to actively generate information and construct connections among different materials and employ them in new situations (Fiorella and Mayer, 2016). Reading and writing skills are generative by nature as they promote learners to select the most relevant information from the lesson, organize it into a coherent structure (e.g. making an outline) and integrate it with prior experience and existed information and produce a new material (e.g. an essay, stating opinions on the passage).

\section{Critical Reading:}

Reading is considered as one of the most difficult and challenging skill for students to learn. Teaching reading to university students should make a shift from just decoding meaning and answering comprehension question to more critical skills. They need to learn how to make sense of the ideas presented in a reading text, to judge them and to identify the tone of the author. Although, these skills are very essential for university student the majority of them lack the ability to deal with them and struggle when they are exposed to any complex texts (Mickelson, 2018).

The learners' ability to make judgments and draw inferences, distinguish between fact and opinion, judge the elements of a text, make connections to personal experience and prior knowledge, see the cause/effect or compare/contrast relationships in the text, and arrive at conclusions are considered core skills of critical reading (McLaughlin and Rasinski, 2015). 
Moreover, critical reading is an active process in which the reader is in a direct dialogue with the writer through which $\mathrm{s} / \mathrm{he}$ is offered the opportunity to think deeply on the positive and negative aspects of a written text, gain different perspectives and write important notes (Douglas et al., 2016).

\section{Critical Writing:}

Writing is another challenging and crucial skill that students face in learning. However, university students should not merely learn to write the correct structure of a paragraph to form a coherent essay, or the mechanics of writing but they need to think more of the different aspects of their piece of writing. Serra (2013) recognized three basic assumptions of the difficulty in learning writing which were: uncomfortable style of writing, unfamiliar topics, inability of developing and expanding their ideas in many paragraphs.

Critical writing is another essential skill for university students to practice self-reflection. To write critically is meant to consider the quality of the evidence and argument one have read and to identify key positive and negative aspects one can comment upon . Learners' ability to write critically should be clear in their ability to convince the readers to accept their ideas through effective reasons and evidence (Ahmed, 2018). Students need to have a "critical voice" in their writing and to find out the different debates in a given topic and reflect on the issues that are required to write on (Cottrell, 2013).

Critical reading and writing are closely related to each other and are essential skills that university students need to demonstrate. Smith (2012) stated that "If we are ever going to create college-level writers, we must begin by creating collegelevel readers". Learning to read and write critically should not be done through traditional ways but through innovative methods of teaching which seek to meaning construction not searching for existing meanings. The GLM is a proposed method 
which provides a positive and comfortable learning environment to achieve this.

\section{Literature Review}

There is a number of studies investigated the effectiveness of implementing GLM in teaching students in different courses. For example, GLM was employed in Mathematics classes and was found of significant use in improving students' achievement level, communication abilities, mathematical reasoning and overall performance. Students also gained a better and deeper understanding of difficult concepts. This improvement was due to the implementation of GLM in their Mathematical courses (e.g. Rahayu and Sugianto, 2019 and Bot, 2018).

In Science, GLM was also efficient and functional on promoting and developing the analytical thinking skills; mastery of physical concepts; academic performance; and achievement level of students. Moreover, it fostered and changed the motivation and attitudes of students towards studying science and was recommended to be used in other courses as it offered a better opportunity for students to learn (e.g. Prawita et al., 2019 and Atsuwe and Anyebe, 2016 ).

Some studies conducted in Arabic in Egypt employing GLM found the model to be effective and useful in improving the metacognitive thinking of students, their achievement and some habits of mind. GLM was significantly positive and beneficial in promoting students' deductive thinking and motivation towards learning (e.g Al-Bitar, 2017 and Abdel Said, 2016).

Studies adopting GLM in teaching language skills are not sufficient in The Arab countries. For example, Basaffar (2017) used GLM to teach reading comprehension to university students in Saudi Arabia aiming to explore its effect on their achievement level in reading. Results demonstrated that the model was effective in improving students' performance in reading comprehension skills and helped to change the class to an entire 
learner-centered one. Jabbari and Sarani (2016) also attempted to investigate the impact of Generative Learning strategies on reading comprehension and recall of literary texts. The study confirmed that the experimental group surpassed the control group on study tests due to the implementation of generative learning strategies. In the same line, the purpose of $\mathrm{Al}-$ Qatawneh's study (2010) was to examine the effect of the GLM on developing Jordanian secondary school students' reading comprehension skills and stimulating strategy awareness in English. Results showed that there was a significant improvement between the control and the experimental group on both the reading comprehension test and the reading strategy awareness questionnaire.

Generally speaking, changing the learning environment from a teacher-centered to a learner-centered which calls for more engagement and involvement of students in learning and in constructing meaning is of great effectiveness in improving critical reading and writing skills. There are some effective and innovative methods that put learners at the foreground of the learning process such as Blended learning (Allam, 2014); WebQuest (Khodary, 2014 and Masoud, 2017) in developing reading skills and Action Research (Ahmed, 2018) and Blended learning (Santosa, 2018) in improving writing skills.

The aforementioned review of literature revealed the utility and effectiveness of GLM in enhancing learners' achievement, performance, critical thinking skills, motivation and reading comprehension in different fields. However, there is still a literature gap in the implementation of the model in language learning classes in the Arab world (e.g. Basaffar, 2017), particularly, in Egypt (e.g. Al-Bitar (2017). Therefore, the researcher advocated conducting the current study hoping to explore the effectiveness of the GLM in fostering students' critical reading and writing skills in Minia University in Egypt. Reviewing the literature also helped to state the hypotheses of 
the study based on the findings of previous studies, design the GLM program and construct the tools of the study: the tests and the questionnaires.

\section{The pilot study}

Two weeks prior the real implementation of the study, the pilot study was conducted in order to estimate the validity and reliability of the study tools. Twenty seven EFL, third year students in the Faculty of Education, Minia University were chosen randomly to apply the pilot study. Face validity of all tools were determined by consulting a panel of experts, whereas the internal validity was measured by internal consistency. The reliability of the all tools was determined by one or more of the following: Cronbach Alpha Coefficient, test-retest, or inter-rater method. The pilot study indicated that all tools were valid and reliable for the real implementation.

To investigate students' need for the current study, two questionnaires were developed. The first questionnaire aimed to find out 2nd year students' knowledge about critical reading skills and how far they apply in the reading classes. The second questionnaire was to investigate students' knowledge about critical writing skills classes how far they apply in the writing classes. When applying the questionnaires, students indicated that in reading classes they only had reading passages followed by different questions to be answered referring to some reading comprehension skills e.g. skimming, scanning and getting the main idea. Also, in writing classes students asserted that they only write paragraphs on different topics referring only to topic sentences, supporting details and conclusions. Results of the pilot questionnaires showed that students they did not have any prior knowledge about critical reading and writing skills.

\section{Statement of the Problem}

The problem of the present research is manifested in $2 \mathrm{nd}$ year English Majors' weakness in their critical reading and 
writing skills. Such weakness may be attributed to the insufficient training and unsuitable strategies given to students in reading and writing classes. In reading and writing sessions, students merely practice word attack skills and comprehension skills and they lack deeper view on texts. Therefore, they need to enhance their reading, whether comprehension or critical, skills as well as their critical writing skills through implementing new techniques which call for more active roles of students in building knowledge.

\section{Objectives of the Study}

The present study was conducted to achieve the following objectives:

- Enhancing critical reading skills of 2nd year English Majors at Faculty of Education through a Generative Learning Model.

- Enhancing critical writing skills of 2nd year English Majors at Faculty of Education through a Generative Learning Model.

\section{Hypotheses of the Study}

- There would be a statistical significant difference between means of scores obtained by the subjects of the treatment and the non treatment groups in the post performance on the overall Critical Reading test (favoring the treatment group).

- There would be a statistical significant difference between means of scores obtained by the subjects of the treatment and the non treatment groups in the post performance on the Critical Reading test domains (favoring the treatment group).

- There would be a statistical significant difference between means of scores obtained by the subjects of the treatment and the non treatment groups in the post performance on the overall Critical Writing test (favoring the treatment group).

- There would be a statistical significant difference between means of scores obtained by the subjects of the treatment and the non treatment groups in the post performance on the Critical Writing test domains (favoring the treatment group). 


\section{Significance of the Study}

The current study aimed at shedding light on critical reading and writing skills mostly needed by English Majors' students. The conventional methods of teaching reading and writing are observed to be of limited value in producing competent learners. The study was undertaken to examine the effectiveness of a program based on GLM technique in fostering 2nd year English Majors' critical reading and writing skills. The study might be significant to pre-service students as it provides an instructional strategy based on knowledge making to develop their critical reading and writing skills. The study tried to fill the gap in the review of literature in Egypt, particularly, in the area of the current study. In addition to this, the present study was expected to be significant in constructing a program particularly directed to pre-service teachers to enhance their critical reading and writing skills.

\section{Delimitations of the Study}

- The study was delimited to 60 second year English majors at the Faculty of Education, Minia University. Second year was chosen particularly, because they are enrolled in a compulsory reading and writing courses in the first and second year. So, they need build more multifaceted skills based on previous knowledge in order to make use of what they learnt in the following years. The treatment lasted for twelve weeks in the second term of the academic year 2019, four hours each week, in addition to another two weeks for applying the pre-posttests.

- Critical Reading skills were limited to the sub skills that are most needed by 2 nd year English majors and these were decided upon after administering a questionnaire on a sample of those students, TEFL staff members and experts. TEFL staff members and experts confirmed that these main skills were suitable for the participants of the research. These skills were: Distinguish between compare and contrast situations in the text; Make inference from a text; Determine the central purpose of the text; 
Identify valid conclusions; Identify the author's tone towards a given topic; Judge the structure of a text; Distinguish between facts and opinions in the text and Examine the evidence the text employs.

- Critical writing skills were limited to the sub skills that are most needed by 2 nd year English majors and these were decided upon after administering a questionnaire on a sample of those students, TEFL staff members and experts. TEFL staff members and experts confirmed that these main skills were suitable for the participants of the research. These skills were: Write a debatable and non-debatable thesis; Write fluent sentences; Choose suitable transition words in a certain text; Write relevant support (details, examples or facts); Write effective conclusions for an essay; Write different writing modes(descriptive, narrative, expository, persuasive); Write an accurate paraphrase of information; and Write an essay in response to ideas.

\section{Definitions of Terms}

\section{Generative Learning}

Business dictionary (2019) defined Generative learning as "Style of learning that incorporates existing knowledge with new ideas based on experimentation and open-mindedness. This style of learning encourages individual and team creativity, resulting in a new way of viewing old methods". Another definition of GLM is provided by (Fiorella and Mayer, 2016) stating that "Generative learning is the process of transforming incoming information (e.g., words and pictures) into usable knowledge (e.g., mental models, schemas).

Generative Learning is operationally defined as an instructional learning model which involves the active process of constructing, selecting, reorganizing and integrating new information with students' prior knowledge.

\section{Critical Reading}

EAP Foundation (2019) defined Critical reading as "it involves questioning a text, rather than assuming everything it contains is 
factual. It is the process of exercising careful judgment and evaluating the evidence".

Another definition is provided by Wikipedia' (2019) definition of Critical reading is "a form of language analysis involves a deeper examination of the claims put forth as well as the supporting points and possible counterarguments. The ability to identify possible ambiguities and flaws in the author's reasoning and address them comprehensively".

The operational definition of Critical reading is the process of generating meaning from the text through distinguishing between facts and opinions, recognizing the writer's tone, make sense of what are being read, making inference and interpretations and to understand the author's intention and perspective.

\section{Critical Writing}

Wikipedia (2019) defined Critical writing as "It involves considering evidence to make reasoned conclusions. Critical writing is writing which evaluates and analyses more than one source in order to develop an argument".

EAP Foundation (2019) gave a simple definition of Critical writing as "the ability to develop an argument or point of view supported by concrete evidence, in other words reasons, examples, and information from sources.

Critical writing is operationally defined as the process of questioning, debating, analyzing all aspects of a topic and logically developing the argument with relevant facts, supports and examples.

\section{Research Design}

A quasi experimental pretest-posttest control group design was employed. A GLM based program, for fostering critical reading and writing skills was developed and used with the randomly chosen treatment group, whereas, conventional 
teaching method was used with the randomly chosen nontreatment group. Thirty male and female students enrolled in the 2nd year in 2019 academic year formed the treatment group and another thirty formed the non-treatment group. The data of the study were gathered by a pre-post CRT and a pre-post CWT. The treatment group was trained using the GLM training program.

\section{Variables of the Study}

\section{Independent Variable}

- Using a GLM based-program.

\section{Dependent Variables}

- Enhancing students' critical reading skills.

- Enhancing students' critical writing skills.

\section{Control Variable}

\section{Level of performance in the Pre- CRT}

The results indicated that the difference in the mean scores between the treatment and non-treatment on the Pre-CRT was not statically significant as shown in the following table.

Table (1) Mean, Standard Deviation and t-value result between mean scores of the Treatment and Non-Treatment groups in the Pre-CRT

\begin{tabular}{c|c|c|c|c|c}
\hline No & Group & Mean & S.D & DF & T-value \\
\hline 30 & Treatment & 17.27 & 3.96 & \multirow{2}{*}{58} & \multirow{2}{*}{0.20} \\
\hline 3
\end{tabular}

Not Significant at $0.01 \& 0.05$ levels

\section{Level of performance in the Pre- CWT}

The results indicated that the difference in the mean scores between the treatment and non-treatment on the Pre- CWT was not statically significant as shown in the following table.

Table (2) Means, Standard Deviation and t-value between mean scores of the Treatment and Non-treatment Groups in the Pre-CWT

\begin{tabular}{c|c|c|c|c|c}
\hline No & Group & Mean & S.D & DF & t-value \\
\hline 30 & Treatment & $\mathbf{2 3 . 8 7}$ & $\mathbf{3 . 0 3}$ & \multirow{2}{*}{5} & \multirow{2}{*}{0.09} \\
\hline 30 & Non-treatment & $\mathbf{2 3 . 8 0}$ & $\mathbf{2 . 9 0}$ & & \\
\hline
\end{tabular}

Not Significant at $0.01 \& 0.05$ levels 


\section{Instruments of the study}

\section{The following Instruments}

- A critical reading skills questionnaire.

- -A critical writing skills questionnaire

- - A critical reading skills test.

- -A critical writing skills test.

\section{The Questionnaires}

- The critical reading skills questionnaire.

- The critical writing skills questionnaire.

In order to answer the questions of the research, two questionnaires were developed. The first questionnaire aimed at specifying the critical reading skills that are most needed by 2ndyear English majors. The second one aimed at figuring out the critical writing skills that students mostly need. Building the questionnaires went through the following steps:

- Reviewing the literature related to the field of critical reading and writing skills.

- Building up the questionnaires following these steps:

- Stating the objectives of the questionnaire

- Stating the sub- skills

- Identifying the opinions of the jury members through the preliminary questionnaires.

\section{The critical Reading Skills Questionnaire}

This questionnaire consisted of fifteen sub-critical reading skills which were tailed into eight ones according to the viewpoint of EFL experts. The jury members confirmed that these are the basic critical reading skills as mostly needed for second year English Majors. These skills were: Distinguish between compare and contrast situations in the text; Make inference from a text; Determine the central purpose of the text; Identify valid 
conclusions; Identify the author's tone towards a given topic; Judge the structure of a text; Distinguish between facts and opinions in the text and Examine the evidence the text employs (See Appendix (A).

\section{The Critical Writing Skills Questionnaire}

This questionnaire consisted of sixteen sub-critical writing skills which were tailed into eight ones according to the viewpoint of EFL experts. The jury members confirmed that these are the basic critical writing skills as mostly needed for second year English Majors. These skills were: Write a debatable and nondebatable thesis; Write fluent sentences; Choose suitable transition words in a certain text; Write relevant support (details, examples or facts); Write effective conclusions for an essay; Write different writing modes(descriptive, narrative, expository, persuasive); Write an accurate paraphrase of information; and Write an essay in response to ideas (See Appendix (A).

\section{Validity of the questionnaires}

A panel of TEFL specialists, the jury members, approved the face validity of the questionnaires, their suitability and necessity for the participants.

\section{The Critical Reading Skills Test}

\section{Objectives}

This test was designed to:

- Assess 2nd year English majors' performance in critical reading skills.

- Ensure equality between the two groups through piloting.

- Measure the degree of improvement after the administration of the treatment.

\section{Test Construction}

The test consisted of twenty MCQ and completion items representing the most important critical reading skills as 
approved by the EFL experts. The test included eleven short passages followed by different questions to be answered. The passages were chosen on the basis of students' familiarity with the topics and the linguistic difficulty and length (See Appendix (A).

\section{Scoring}

The score was simply the total number of correctly marked answer. Two points were given for each test item. The total score of the test was (40).

\section{Testing Time}

During piloting the test, time taken by each student finishing the test was calculated and the average was found to be nearly 120 minutes. Thus, the testing time was two hours.

\section{Validity of the Test}

\section{Face Validity of the Test}

A group of twenty seven 2nd English Majors, Primary Section, were selected for piloting the test. The test was submitted to a jury of 8 qualified and experienced TEFL specialists. They were requested to judge the linguistic stating of the items, appropriateness, clarity of the test instructions, the difficulty level, length of the test, applicability, fitness of the items for the participants, and how far the items measure the skill it is intended to measure. Their suggestions were taken into consideration. The jury members confirmed the suitability and applicability of the test for the study participants.

\section{The Internal Consistency of the Test Items}

The validity of the test was determined by computing internal consistency of each item by using (Pearson correlation formula). Correlation coefficients between each item and the total sheet of CRT ranged from 0.449 to 0.868 (See Appendix (C).

Correlation coefficients and Alpha between each domain and the total sheet of the CRT were significant with all domains which 
indicated that the test had a high validity as shown in the following table:

Table (3) Correlation Coefficients \&Alpha between each domain and the total sheet of CRT

\begin{tabular}{|c|c|c|c|}
\hline No & Domain & $\mathbf{R}$ & Alpha \\
\hline 1. & Determine the central purpose of the text & 0.532* & 0.834* \\
\hline 2. & Make inferences from the text & $0.479 * *$ & $0.806 *$ \\
\hline 3. & Identify valid conclusions & 0.717* & 0.707* \\
\hline 4. & Identify the author's attitude and Tone & $0.621 *$ & 0.791* \\
\hline 5. & Distinguish Compare and contrast ideas & $0.644 *$ & 0.707 \\
\hline 6. & Distinguish Cause and effect & 0.732* & 0.774* \\
\hline 7. & Distinguish Facts and Opinions & $0.550 *$ & $0.615 *$ \\
\hline 8. & Identify the evidence the text employs & $0.841 *$ & 0.739* \\
\hline
\end{tabular}

*Significant at 0.01 level **Significant at 0.05 level

\section{The Reliability of the Test}

The data obtained from administrating the test in the pilot study was computed to calculate the reliability coefficient. The reliability coefficient of the test was determined by the testretest method. The statistical correlation was significant but and $\mathrm{t}$-value was not significant. To ensure the reliability of the test Cronbach Alpha Coefficient was calculated and it was 0.953. This indicates that the CRT enjoys a high degree of reliability as shown in the following table:

Table (4) Correlation Coefficient and Alpha's reliability Coefficient between mean scores

of the test-re-test of CRT

\begin{tabular}{c|c|c|c|c|c|c|c}
\hline No & Group & Mean & SD & DF & t.value & R & Alpha \\
\hline \multirow{2}{*}{27} & Test & $\mathbf{2 0 . 4 4}$ & 5.00 & \multirow{2}{*}{25} & \multirow{2}{*}{$0.16 * *$} & \multirow{2}{*}{$0.972 *$} & \multirow{2}{*}{$0.953 *$} \\
\cline { 2 - 5 } & Re-test & 20.67 & 5.21 & & & & \\
\hline
\end{tabular}

*Significant at 0.01 level $\quad$ **Not Significant at 0.01 \& 0.05 levels

\section{Item Analysis}

\section{Item Difficulty and Discrimination Power}

Responses to individual items were analyzed to determine item difficulty and facility index and discrimination power of this test. 
The difficulty index of each item ranged from 0.333 to 0.667 . Hence, the difficulty index of the items of this test is acceptable. Item Discrimination was calculated to determine how well each item discriminates between high and low achievers. The discriminating items are those answered correctly by more of the higher group than of the lower one. Discrimination power ranged between 0.333and 0.667 (See Appendix (C).

\section{The Critical Writing Skills Test}

\section{Objectives}

This test was designed to:

- Assess 2nd year English majors' performance in critical writing skills.

- Ensure equality between the two groups through piloting.

- Measure the degree of improvement after the administration of the treatment.

\section{Test Construction}

The test consisted of ten different types of questions representing the most important critical writing skills as approved by the EFL experts. There were closed and open-ended questions. Each question had certain instructions to follow (See Appendix (A).

\section{The test included the following items:}

- Identify the writing mode of the passage (Two questions)

- Write a good conclusion of a paragraph (Two questions)

- Write a fluent paragraph (One question)

- Write debatable and non-debatable statement (Two questions)

- Write a good paraphrase (One question)

- Write supporting details and ideas (One question)

- Write an essay(One question)

\section{Scoring}

The total score of the test was 50. Points given for each test item vary according to the type of question and response required 
from the participants. Two raters (the researcher and another colleague) participated in the correction of open-ended questions and the average was taken to be the score of each student. The reliability coefficient between the two raters was calculated to establish reliability of the test which was 0.834 . A scoring rubric was developed by to grade students' paragraphs and essays. The essay writing performance was corrected on the basis of the following criteria:

- Organization.

- Mechanics of writing.

- Sentence structure.

- Word choice.

\section{Testing Time}

The test time was calculated applying the same procedures mentioned above. So, the average time was found to be nearly 180 minutes. Thus, the testing time was three hours.

\section{Validity of the Test}

\section{Face Validity of the Test}

Following the same procedures implemented above, the test was submitted to a jury of 8 qualified and experienced TEFL specialists. They were requested to judge the linguistic stating of the items, appropriateness, clarity of the test instructions, the difficulty level, length of the test, applicability, fitness of the items for the participants, and how far the items measure the skill it is intended to measure. Their suggestions were taken into consideration. The jury members confirmed the suitability and applicability of the test for the study participants.

\section{The Internal Consistency of the Test Items}

The validity of the test was determined by computing internal consistency of each item and the total sheet by using (Pearson correlation formula). Correlation coefficients ranged from 0.420 to 0.781 for the close-ended questions and ranged from 0.573 to 
0.769 for the open-ended questions (See Appendix (C).Correlation and Alpha between each domain and the total sheet of the CWT were significant with all domains which indicated that the test had a high validity as shown in the following table:

Table (5) Correlation Coefficients \&Alpha between each domain and the total sheet of CWT

\begin{tabular}{|c|l|c|c|}
\hline No & \multicolumn{1}{|c|}{ Domain } & R & Alpha \\
\hline 1. & Write a debatable and non-debatable thesis & $\mathbf{0 . 6 9 2}^{*}$ & $\mathbf{0 . 9 5 8 *}$ \\
\hline 2. & Write fluent sentences. & $\mathbf{0 . 8 6 1} *$ & $\mathbf{0 . 7 3 2}^{*}$ \\
\hline 3. & Choose suitable transition words in a text & $\mathbf{0 . 6 9 1}^{*}$ & $\mathbf{0 . 8 4 9}^{*}$ \\
\hline 4. & Write relevant support (details, facts, etc.) & $\mathbf{0 . 5 4 9}^{*}$ & $\mathbf{0 . 8 2 8}^{*}$ \\
\hline 5. & Write effective conclusions for an essay. & $\mathbf{0 . 8 8 2}^{*}$ & $\mathbf{0 . 8 8 1}^{*}$ \\
\hline 6. & $\begin{array}{l}\text { Write different writing modes(descriptive, } \\
\text { narrative, expository, persuasive) }\end{array}$ & $\mathbf{0 . 8 2 2}^{*}$ & $\mathbf{0 . 8 7 0}^{*}$ \\
\hline 7. & Write an accurate paraphrase of information & $\mathbf{0 . 6 0 3}^{*}$ & $\mathbf{0 . 5 4 6}^{*}$ \\
\hline 8. & Write an essay in response to ideas & $\mathbf{0 . 8 1 9}^{*}$ & $\mathbf{0 . 8 4 0}^{*}$ \\
\hline
\end{tabular}

*Significant at 0.01 level

\section{The Reliability of the Test}

The reliability coefficient of the test was determined by Cronbach Alpha Coefficient for the difficulty of applying test-re-test with the two raters. Reliability coefficient was statistically significant which indicates that the CWT enjoys a high degree of reliability as presented in the following table:

Table (6) Cronbach Alpha's reliability coefficient of the CWT

\begin{tabular}{|c|c|c|}
\hline No & Variable & Alpha \\
\hline 27 & Critical Writing & $\mathbf{0 . 9 7 1} *$ \\
\hline
\end{tabular}

*Significant at 0.01 level

\section{Item Analysis}

\section{Item Difficulty and Discrimination Power}

Responses to individual items were analyzed to determine item difficulty and facility index and discrimination power of this test. The difficulty index of each item ranged from 0.333 to 0.655 . Hence, the difficulty index of the items of this test is acceptable. 
Item Discrimination was calculated to determine how well each item discriminates between high and low achievers. The discriminating items are those answered correctly by more of the higher group than of the lower one. Discrimination power ranged between 0.333 and 0.666 (See Appendix (c).

\section{Teaching and Training the Treatment Group}

1. The treatment group was taught using the GLM program that was developed by the researcher. The implementation of the research lasted for 12 weeks (four hours each week). The session started with posing a question to arouse students' interest and motivation followed by a discussion of the importance of using a GLM and the main Critical reading and Writing skills that they mostly needed.

2. According to the SOI model which was employed in this study, the training session was divided into three basic phases (Select, Organize and Integrate). The instructor put the rules and procedures which should be followed throughout the training program.

3. The Select Phase: It is considered as a preliminary step in which curiosity and interest of students are aroused towards the new topic through a warming up activity. Students were provided with some prompts with some related videos and images concerning the new topic. This assisted the students to search in their memories for the relevant information and to explore ideas related to daily life experiences or gained from previously learned situations. Then, students were then encouraged to ask and answer questions related to the images observed and implement activities that require knowledge generation (e.g. recognizing the structure of a text, making inferences, comparing and contrasting, writing debates and valid conclusion, writing different writing modes, etc.)

4. While discussing the new topic in groups, students were encouraged to make debates, share ideas and sometimes, 
search for other related ideas on the Internet in class to select the most relevant information in consistent with their prior knowledge.

5. The Organize Phase: It is considered as a challenging and focusing phase. In this stage, students were encouraged to make links and connections between the newly learned material and their previous information on this particular topic. They add the information to their memory and then try to find and memorize the new one. As students were divided into groups, they were also given the opportunity to express their own views, ideas and experiences on the topic and also to compare them with their friends in other groups. Students were using different activities e.g. gap filling, puzzles, role playing, making dialogues on the ideas of the learned material to make links with already existed knowledge. Students were also given the opportunity to practice the different skills whether in class or through doing online activities and sent them to the instructor for feedback. Each group had a different task to execute within the group and then share it in public with the whole class. Tasks included distinguishing facts and opinions; recognizing cause/effect relations, writing valid conclusion and fluent sentences, generated critical questions on the topic, wrote evidence from the text, and generated various titles, etc.

6. The Integrate Stage: It is the application phase of the model, which implies presenting the new ideas and skills in different forms and representation. It is also the stage of recalling already existed information and integrating it with the newly learned one. Therefore, they maintained the new information that is inconsistent with their own information and get rid of the irrelevant one. Students were presenting the newly learned material in a new form. For example, they presented the main purpose of a reading text in a form of mind maps, created different scenarios from the text and sometimes acted those in class. They converted the writing or the reading texts, in some cases, into drawings and dialogues generated by their own interpretations of the debates and arguments. Students, in this 
stage, generated their own meaningful statements about what they have read and learned. Ways of transferring the texts into another form of representation were actively and effectively employed.

\section{Results}

The main concern of the current study was to explore how effective teaching critical reading and writing was through GLM on the treatment group. The "t-test" was utilized for the analysis of data obtained from the CRT and the CWT. Scores of the participants for the pre-post design were analyzed and compared.

\section{Hypothesis (1)}

Analysis of data showed that the treatment group achieved a higher degree of improvement compared with the non-treatment group on the post CRT. A significant difference of the mean scores between the two groups in favor of the treatment group was found since t-value was 10.63 and Eta- squared was 0.952 . Results also pointed out that there was a statistically significant difference in the mean scores of the treatment group between the pre and post administrations of the test as t-value was 11.13 and Eta- squared was 0.936. Consequently, the first hypothesis was confirmed and accepted as shown in the following tables:

Table (7) Means, Standard Deviation, $t$-value result \& $\eta 2$ between mean scores of the Treatment and Non-treatment Groups on the Post-CRT

\begin{tabular}{|c|c|c|c|c|c|c|}
\hline No & Group & Mean & S.D & DF & t-value & $\eta^{2}$ \\
\hline 30 & Treatment & 29.53 & 4.25 & \multirow[b]{2}{*}{58} & \multirow[b]{2}{*}{$10.63 *$} & \multirow[b]{2}{*}{$0.952 *$} \\
\hline 30 & $\begin{array}{c}\text { Non- } \\
\text { treatment }\end{array}$ & 17.73 & 4.52 & & & \\
\hline
\end{tabular}

* Significant at 0.01 level

Table (8) Means, Standard Deviation, $t$-value \& $\eta 2$ between mean scores of the Treatment Group in the Pre-Post-CRT

\begin{tabular}{|c|c|c|c|c|c|c|}
\hline No & Treatment & Mean & S.D & DF & t-value & $\eta^{2}$ \\
\hline 30 & Pre & 17.27 & 4.52 & \multirow{2}{*}{58} & \multirow{2}{*}{$11.13^{*}$} & \multirow{2}{*}{$0.936^{*}$} \\
\hline 30 & Post & 29.53 & 4.52 & & & \\
\hline
\end{tabular}

* Significant at 0.01 level 


\section{Hypothesis (2)}

Results indicated that the treatment group achieved a significant improvement on each domain of the post CRT. There was a statistically significant difference in the mean scores between the treatment group and non-treatment as t-value for domains ranged from 4.79 to 10.51 and Eta- squared ranged from 0.682 to 820. A statistically significant difference was found in the mean scores of the treatment group between the pre-post administrations of CRT in each domain. Students performed better in some domains rather than others such as: distinguish compare and contrast ideas, identify the author's tone and distinguish facts and opinions as t-value and Eta- squared were high as shown in the following table:

Table (9) Means, Standard Deviation and t-value \& $\eta 2$ between mean scores of the Treatment Group in the Pre-Post CRT domains

\begin{tabular}{|c|c|c|c|c|c|c|}
\hline \multirow{2}{*}{ Domain } & \multicolumn{2}{|c|}{ Mean } & \multicolumn{2}{|c|}{ SD } & \multirow{2}{*}{$\begin{array}{c}\text { t- } \\
\text { value }\end{array}$} & \multirow{2}{*}{$\eta^{2}$} \\
\hline & Pre & Post & Pre & Post & & \\
\hline $\begin{array}{l}\text { 1. Determine the } \\
\text { central purpose of } \\
\text { the text }\end{array}$ & 2.60 & 4.33 & 1.38 & 1.37 & $4.79 * *$ & $0.684 *$ \\
\hline $\begin{array}{l}\text { 2. Make inferences } \\
\text { from the text }\end{array}$ & 2.73 & 4.47 & 1.82 & 1.33 & $8.13 *$ & $0.874 *$ \\
\hline $\begin{array}{l}\text { 3. Identify valid } \\
\text { conclusions }\end{array}$ & 1.3 & 3.27 & 1.33 & 0.96 & $6.67 *$ & $0.805^{*}$ \\
\hline $\begin{array}{l}\text { 4. Identify the } \\
\text { author's Tone }\end{array}$ & 2.93 & 4.33 & 1.61 & 1.27 & $9.67 *$ & $0.932 *$ \\
\hline $\begin{array}{l}\text { 5. Distinguish } \\
\text { Compare and } \\
\text { contrast ideas }\end{array}$ & 1.3 & 2.67 & 0.85 & 0.99 & $10.51 *$ & $0.928 *$ \\
\hline $\begin{array}{l}\text { 6. Distinguish } \\
\text { Cause and effect }\end{array}$ & 1.53 & 3.13 & 1.23 & 0.99 & $8.45^{*}$ & $0.864 *$ \\
\hline $\begin{array}{l}\text { 7. Distinguish Facts } \\
\text { and Opinions }\end{array}$ & 1.93 & 2.67 & 0.81 & 0.94 & $9.17 *$ & 0.894* \\
\hline $\begin{array}{l}\text { 8. Identify the } \\
\text { evidence the text } \\
\text { employs }\end{array}$ & 2.53 & 4.47 & 1.78 & 1.23 & $4.80 * *$ & 0.723* \\
\hline
\end{tabular}


Analysis of the data presented in the above table indicates an overall progress and improvement in the performance of the treatment group more than the non-treatment one due to the exposure of the treatment group to learning through the GLM. The model was of great effectiveness in enhancing the different domains of critical reading skills employed in the study. Therefore, the second hypothesis was confirmed and approved.

\section{Hypothesis (3)}

Findings revealed that the treatment group surpassed the nontreatment group on the post CWT. There was a statistically significant difference of the mean scores between the two groups in favor of the treatment group since t-value was 13.37 and Etasquared was 0.951 . Results also pointed out that the difference in the mean scores of the treatment group between the pre and post administrations of the test was statistically significant as tvalue was 13.69 and Eta- squared was 0.942. Consequently, the third hypothesis proved and accepted as shown in the following tables:

Table (10) Means, Standard Deviation, $t$-value result \& $\eta 2$ between mean scores of the Treatment and Non-treatment Groups on the Post- CWT

\begin{tabular}{|c|c|c|c|c|c|c|}
\hline No & Group & Mean & S.D & DF & t-value & $\eta^{2}$ \\
\hline 30 & Treatment & 37.90 & 4.61 & \multirow{2}{*}{58} & 13.37 & \multirow{2}{*}{0.95} \\
\hline 30 & Non-treatment & 24.13 & 2.80 & & & \\
\hline
\end{tabular}

* Significant at 0.01 level

Table (11) Means, Standard Deviation and t-value \& $\eta 2$ between mean scores of the Treatment Group in the Pre- Post-CWT

\begin{tabular}{|c|c|c|c|c|c|c|}
\hline No & Treatment & Mean & S.D & DF & t-value & $\eta^{2}$ \\
\hline 30 & Pre & 23.87 & 3.03 & \multirow{2}{*}{58} & \multirow{2}{*}{$13.69 *$} & \multirow{2}{*}{$0.942 *$} \\
\hline 30 & Post & 37.90 & 4.61 & & & \\
\hline
\end{tabular}

* Significant at 0.01 level

\section{Hypothesis (4)}

Analysis of data indicated that the treatment group achieved a significant improvement on each domain of the post CWT. There was a statistically significant difference in the mean scores 
between the treatment group and non-treatment as t-value for domains ranged from 3.79 to 10.13 and Eta- squared ranged from 0.677 to 0.956 (See Appendix (C). The difference in the mean scores of the treatment group between the pre-post administrations of CWT in each domain was statistically significant. Results also showed that students got high marks on particular critical writing skills such as: write an essay in response to idea, write an accurate paraphrase of information and write different writing modes as t-values and Eta- squared were high as shown in the following table:

Table (12) Means, Standard Deviation and t-value \& $\eta^{2}$ between mean scores of the Treatment Group in the Pre-Post-Critical Writing Test domains

\begin{tabular}{|c|c|c|c|c|c|c|}
\hline \multirow{2}{*}{ Domain } & \multicolumn{2}{|c|}{ Mean } & \multicolumn{2}{c|}{ SD } & t- & \multirow{2}{*}{$\eta^{2}$} \\
\cline { 2 - 6 } & Pre & Post & Pre & Post & value & \\
\hline $\begin{array}{c}\text { 1.Write a debatable and } \\
\text { non-debatable thesis }\end{array}$ & 2.10 & 3.90 & 1.37 & 1.92 & $5.10^{*}$ & $0.636^{*}$ \\
\hline $\begin{array}{c}\text { 2. Write fluent } \\
\text { sentences. }\end{array}$ & 1.87 & 3.13 & 0.72 & 0.99 & $5.57^{*}$ & $0.797^{*}$ \\
\hline $\begin{array}{l}\text { 3. Choose suitable } \\
\text { transition words in a } \\
\text { certain text }\end{array}$ & 2.23 & 4.17 & 080 & 0.93 & $6.45^{*}$ & $0.848^{*}$ \\
\hline $\begin{array}{c}\text { 4. Write relevant } \\
\text { support } \\
\text { examples or facts) }\end{array}$ & 4.40 & 6.57 & 1.05 & 0.96 & $8.21^{*}$ & $0.946^{*}$ \\
\hline $\begin{array}{c}\text { 5. Write effective } \\
\text { conclusions for an essay. }\end{array}$ & 2.07 & 3.47 & 1.41 & 1.02 & $5.32^{*}$ & $0.730^{*}$ \\
\hline $\begin{array}{c}\text { 6.Write different } \\
\text { writing modes }\end{array}$ & 2.07 & 3.40 & 1.21 & 0.92 & $8.73^{*}$ & $0.936^{*}$ \\
\hline $\begin{array}{c}\text { 7. Write an accurate } \\
\text { paraphrase of } \\
\text { information }\end{array}$ & 3.77 & 4.63 & 0.62 & 0.75 & $8.80^{*}$ & $0.958^{*}$ \\
\hline $\begin{array}{c}\text { 8. Write an essay in } \\
\text { response to ideas }\end{array}$ & 5.37 & 8.63 & 1.02 & 1.56 & $9.45^{*}$ & $0.946^{*}$ \\
\hline
\end{tabular}

*Significant at 0.01 level

Analysis of the data presented in the above tables indicates significant progress in the performance of the treatment group more than the non-treatment one. It also indicates a significant improvement in the performance of the treatment group in each 
domain of the CWT. This increase is due to the exposure of the treatment group to learning through the GLM. The model was very useful and efficient in enhancing the different domains of the critical writing skills employed in study. Therefore, the fourth hypothesis is proved and accepted.

\section{Discussion}

From the aforementioned findings of the study, there was evidence of an overall improvement in the performance of the participants of study. The treatment group surpassed and outperformed the non-treatment group as they achieved higher scores on both the critical reading and writing tests. This significant improvement and increase are in students' scores are attributed to the implementation of GLM on teaching and training the treatment group. Statistical results indicated that students typically enjoyed some domains and gained a deep understanding of their different sub-skills whereas they found difficulty to deal with others. This was evidently clear from the significant differences in t-value among the domains presented in the findings of the study.

Using the GLM training program in the current study was of great effectiveness for students in many ways as it offered a collaborative, an encouraging and a positive environment which made them so excited and eager to work. Such an environment is so crucial for effective learning as confirmed by Douglas et al. (2016). It increased the active participation and involvement of all students in creating meaning and constructing knowledge. Throughout the training sessions, more mental and meaningful tasks and structures were executed in regard to knowledge and information presented in different activities. The GLM helped students to have deeper understanding of the ideas in the given reading texts and more reflective and critical views on topics to write about. It also significantly promoted and boosted their critical reading and writing skills. Students were obviously able to recognize the different tones of the writer and make more apparent connections to prior knowledge. 
It is pertinent to declare that dividing the session into three basic stages (SOI) was of great value and usefulness for students to acquire the different critical reading and writing skills through a step-by-step model. The different phases of the GLM helped the students to have enough time to acquire and practice the specific skill in class and also have extra meaningful activities online. The Select stage encourages students to be more involved in planning and organizing their future learning and they no longer feel shy or afraid of expressing their ideas or view points. Students were also able to search and find out the most relevant material that is in consistent with their own which made it easier to learn (Rahayu and Sugianto, 2019). . Students made considerable gains in distinguishing between what they already had and the new material as mentioned by one of the student "really select step helps me to see where I am and where I can start". Preparing students in advance helped the instructor to get an accurate insight of their real abilities and skills. This phase was considered as the paved way and the starting point for them to for the next. It helped the instructor to have a closer look on the way students think and perform.

The Organize stage helped the students to apply the newly learned knowledge they got while discussion and interaction, within the groups and with the instructor in the previous phase. They were encouraged to keep up collaborative exchange of knowledge and information where they supported each other in their performance. During this stage, students began to generate the main purpose of the text, paraphrase texts, generate titles, generate questions, express themselves through different presentations in class or online. Increasingly, they began to develop more critical ideas in reading and have a clear critical voice in writing. They were encouraged to keep up collaborative exchange of knowledge and information where they supported each other in their performance. The kind of discussion and argument held among students helped them to gain self- 
confidence in expressing their own opinions and giving evidence for them. This was stated by many students, e.g."I become more confident to deal with difficult and challenging tasks". Another said "Now I feel confident to talk and say what I think and also compare it with my friends to find out whether it is right or wrong".

Students found themselves active and busy all through the training program and particularly, in the Integrate stage where they became more generative, creative and imaginative. In this stage, in addition to applying and executing the above tasks, they started to transfer the reading or writing materials to a new form of representation and search for various web resources to support their presentation. These meaningful and enjoyable activities and tasks not only assisted students acquire deeper understanding and develop interpersonal skills but also gave them authentic experiences that will help them be successful in their future. Students actively and lovely participated in all the activities of the program. They were interested in practicing new activities different from the regular ones they used to do. Providing students with online activities greatly helped them to identify relations among topics and ideas and relating the activities and tasks to everyday life events made students more interested and motivated to learn. Adding to this, giving students the opportunity to search for passages to read and topics that are convenient for them to write on, made them feel that they completely depended on themselves for knowledge generation which is the essence of GLM (Prawita et al., 2019). Many students reflected on this saying ("I was so happy when I think to make a different shape for the reading passage such as drawings which helps me to see it in from another side."; "Really, this stage was very valuable as it widens my mind and made me understand more"; "Really I feel free to choose what to read to understand more and be able to reflect on its ideas easily"; " reading session for me was so difficult and boring but I feel better now at least I 
can choose the passage I like to read and give my opinion"; I liked working online with the teacher and friends to share and discuss our ideas" (For more reflections, see appendix (C).

Furthermore, encouraging students to evaluate and compare their own and others performance enabled them to direct and control their own learning as they paid more attention to their points of strength and weakness. This also motivated them to become more willing to self-correct and gain the skill of constructing and rebuilding their knowledge and making modification and improvements in their understanding and presentation. Actually, providing students with feedback, whether teacher or collegial, on how they use these skills and apply the acquired knowledge not only helped to create more positive relationships among students, but it also helped to increase their progress and critical skills. It is remarkable that GLM was so effective and significant in enhancing students' critical reading and writing skills. In general, GLM provided opportunities for students to learn new knowledge and empirical skills effectively and actively in a natural context.

\section{Conclusion}

Findings of the study reflect the efficacy of the GLM in developing and promoting students' critical reading and writing skills. Students of the treatment group highlighted the benefits that they gain of using the GLM. They indicated that they enjoyed the different steps of the model which were very motivating and interesting.

Throughout the training program, students were enabled to discuss, generate and share ideas whether with their friends or the instructor which they stressed to be very effective and interesting. It also enabled them to have a deeper understanding of the different tasks, skills and activities given and made them fully immersed in learning. It provided them with an impressive learning environment which gave students a great opportunity to 
build up and generate their knowledge. Students were satisfied with learning through performing their activities and tasks in front of the whole group which gave them more confidence and challenge to get rid of tension and pressure when facing the same situation. They appreciated the model as learning and training tool for enriching their critical skills. These results are in consistent with (Abdel Said, 2016, Basaffar, 2017 and Prawita et al. (2019).

Undoubtedly, results gained from analysis of data are clear empirical evidence that the GLM works effectively. In addition, it assisted students to acquire different skills which they will basically benefit from in the following years of learning and lately in their prospective teaching profession.

\section{Suggestions for further Research}

As GLM is in its infant state, more empirical studies need to be conducted to assess its effect. Studies could be done to investigate:

1. Using GLM for developing students' motivation and metacognitive skills.

2. Implementing GLM to improve students' presentation skills.

3. Using GL strategies for enhancing students' learning attitudes and self-efficacy.

4. The effectiveness of using GLM in promoting students' achievement level and self-esteem.

5. The effectiveness of using GLM on enhancing students' speaking and listening skills.

\section{References}

- Abdel Said, A.A. (2016). The effectiveness of Teaching According to a Generative Learning Model to Promote Achievement and Some Habits of Mind of 3rd Year Home Economy Female Students of the Faculty of Specific Education. Arabic Studies in Specific Education Fields, (2), 89-160. 
- Ahmed, K. (2018). Teaching Critical Thinking and Writing in Higher Education: an Action Research Project. TEAN Journal, 10(1), 74-84.

- Al-Bitar, H.M. (2017). Using Generative Learning Strategy to Teach Surveying Course To Develop Surveying Devices Maintenance Skills and Meta-Cognitive Thinking for Second Year Industrial School Students. Journal of Research in Education, Assuit University, 3 (33), 502-580.

- Allam, M. (2014). The Effect of a Program Based on Using Blended Learning on Developing Critical Reading Skills of EFL Secondary Stage Students. Faculty of Education, Ain Shams University.

- Al-Qatawneh, K.S. (2010). The Effect of the Reciprocal Teaching method on Enhancing Critical Reading to skills of Jordanian Secondary School student. European Journal of Social Sciences, 34(1), 767-780. Retrieved from: http://proxy1.ncu.edu.

- Anderman, E. M. (2010). Reflections on Wittrock's Generative Model of Learning: A Motivation Perspective. Educational Psychologist, 45(1), 55-60.

- Atsuwe, B.A and Anyebe, E.N. (2016). Effect of Generative Instructional Strategy on Senior Secondary School Students' Performance. International Journal for Social Studies,(02),40-48 www.edupediapublications.org.

- Basaffar, M.F. (2017). The Effect of Implementing Some Generative Learning Model Strategies in Teaching Reading Comprehension. International Journal of English Language Education, 1 (5), 42-53.

- Business dictionary (2019). http://www.businessdictionary.com.

- Bot, D.T. (2018). On The Effects of Generative Learning Strategy on Students' Understanding and Performance in Geometry. International Journal of Humanities and Social Science Invention (IJHSSI), 7(3), 51-58.

- Cottrell, S. (2013). The Study Skills Handbook (4th ed.), Basingstoke: Palgrave MacMillan.

- Douglas, K., Barnett, T., Poletti, A., Seaboyer, J., and Kennedy, R. (2016). Building reading resilience: Re-thinking reading for the literary studies classroom. Higher Education Research and Development, 35(2), 254-266. 
- EAP Foundation (2019). https://www.eapfoundation.com.

- Fiorella, L. and Mayer, R. E. (2016). Eight ways to promote generative learning. Educational Psychology Review, 28(4), 717741.

- Jabbari, A. A. and Sarani, A. (2016). The Effect of Generative Study Strategies on EFL Learners' Reading Comprehension and Recall of Short Stories. ICT for Language Learning. (03), 45-56. https://www.researchgate.net.

- Hanke, U. (2012) Generative Teaching: Improvement of Generative Learning. In: Seel N.M. (eds) Encyclopedia of the Sciences of Learning. Springer, Boston, MA.

- Khodary, M. (2014). The Effect of a WebQuest Model to Develop Critical Reading Performance among General Secondary Stage Students in Egypt. Journal of Education and Psychology, 12 (4), 14-54.

- McLaughlin, M. and Rasinski, T. (2015). Reaching struggling readers. Reading Today, 32(6), 36-37.

- Masoud, H.M.A. (2017). Using a WebQuest Based-Program in Fostering English Majors' Reading Comprehension Skills and Their Attitudes Towards Reading. Egyptian Council for Curriculum and Instruction. (228), 42-77.

- Mayer, R. E. (2014). Cognitive theory of multimedia learning. In R. E.Mayer (Ed.), The Cambridge handbook of multimedia learning, $2^{\text {nd }}$ Edition, Cambridge University Press.

- Mickelson, N. (2018). Cultivating Critical Reading: Using Creative Assignments to Promote Agency, Persistence, and Enjoyment. Teaching and Learning Journal, 11(1), 1-14.

- Prawita, W., Prayitno, B. A., and Sugiyarto (2019). Effectiveness of a Generative Learning-Based Biology Module to Improve the Analytical Thinking Skills of the Students with High and Low Reading Motivation. International Journal of Instruction, 12(1), 1459-1476.

- Rahayu, R. and Sugianto, M. (2019). Mathematics Teaching Using Generative Learning Model with Character Building Content Aided by Interactive Learning Media. Journal of Mathematics Education Research 8(1) 35-48.

- Santosa, H. M. (2018). The Effect of Blended Learning with Schoology on Students' Writing. https://www.researchgate.net. 
- Serra, R. (2013). How to help young English language learners love writing. Available on line at: http:// blog.britishcouncil.org.

- Smith, C. H. (2012). Interrogating texts: From deferent to efferent and aesthetic reading practices. Journal of Basic Writing, 31(1), 59-79.

- Wikipedia (2019). https://en.wikipedia.org.

- Wittrock, M. C. (1974). Learning as a generative process. Educational Psychologist, 11(2), 87-95.

- Wittrock, M. C. (1992). Generative learning processes of the brain. Educational Psychologist, 27(4), 531-541. 